\title{
Interaction Between Graphene-Coated SiC Single Crystal and Liquid Copper
}

\author{
M. Homa, N. Sobczak, J.J. Sobczak, A. Kudyba, G. Bruzda, R. Nowak, K. Pietrzak, M. Chmielewski, and W. Strupiński
}

(Submitted December 23, 2017; published online April 13, 2018)

\begin{abstract}
The wettability of graphene-coated $\mathrm{SiC}$ single crystal $\left(\mathrm{C}_{\mathrm{Gn}} / \mathrm{SiC}^{\mathrm{sc}}\right)$ by liquid $\mathrm{Cu}(99.99 \%)$ was investigated by a sessile drop method in vacuum conditions at temperature of $1100{ }^{\circ} \mathrm{C}$. The graphene layer was produced via a chemical vapor deposition routine using $4 \mathrm{H}-\mathrm{SiC}$ single crystal cut out from $6^{\prime \prime}$ wafer. A dispensed drop technique combined with a non-contact heating of a couple of materials was applied. The Cu drop was squeezed from a graphite capillary and deposited on the substrate directly in a vacuum chamber. The first $\mathrm{Cu}$ drop did not wet the $\mathrm{C}_{\mathrm{Gn}} / \mathrm{SiC}^{\text {sc }}$ substrate and showed a lack of adhesion to the substrate: the falling $\mathrm{Cu}$ drop only touched the substrate forming a contact angle of $\theta_{0}=121^{\circ}$ and then immediately rolled like a ball along the substrate surface. After settling near the edge of the substrate in about $0.15 \mathrm{~s}$, the $\mathrm{Cu}$ drop formed an asymmetric shape with the right and left contact angles of different values $\left(\theta_{R}=86^{\circ}\right.$ and $\theta_{L}=70^{\circ}$, respectively), while in the next $30 \mathrm{~min}, \theta_{\mathrm{R}}$ and $\theta_{\mathrm{L}}$ achieved the same final value of $\sim 52^{\circ}$. The second $\mathrm{Cu}$ drop was put down on the displacement path of the first drop, and immediately after the deposition, it also did not wet the substrate $\left(\theta=123^{\circ}\right)$. This drop kept symmetry and the primary position, but its wetting behavior was unusual: both $\theta_{\mathrm{R}}$ and $\theta_{\mathrm{L}}$ decreased in $17 \mathrm{~min}$ to the value of $23^{\circ}$ and next, they increased to a final value of $65^{\circ}$. Visual observations revealed a presence of $\sim 2.5$-mm-thick interfacial phase layer reactively formed under the second drop. Scanning electron microscopy (SEM) investigations revealed the presence of carbon-enriched precipitates on the top surface of the first $\mathrm{Cu}$ drop. These precipitates were identified by the Raman spectroscopy as double-layer graphene. The Raman spectrum taken from the substrate far from the drop revealed the presence of graphene, while that obtained from the first drop displacement path exhibited a decreased intensity of $2 D$ peak. The results of SEM investigations and Raman spectroscopy studies suggest that the presence of graphene layer on the $\mathrm{SiC}$ substrate suppresses but does not completely prevent chemical interaction between liquid $\mathrm{Cu}$ drop and $\mathrm{SiC}$. Both chemical degradation (etching) and mechanical degradation of the graphene layer during drop rolling due to high adhesion of the $\mathrm{Cu}$ drop to the $\mathrm{SiC}$ substrate are responsible for mass transfer through the 2nd drop/substrate interface that in turn results in significant changes of structure and chemistry of the drop and the interface.
\end{abstract}

Keywords graphene, liquid $\mathrm{Cu}$, Raman spectroscopy, reactivity, sessile drop, wettability

\section{Introduction}

In recent years, the outstanding properties of carbon nanotubes and graphene have inspired the researchers with the idea of its possible use in metal matrix composites (MMCs) as a constituent significantly improving thermal properties (thermal conductivity and thermal expansion) of these materials, particularly important for thermal management applications

Electronic supplementary material The online version of this article (https://doi.org/10.1007/s11665-018-3340-8) contains supple mentary material, which is available to authorized users.

M. Homa, J.J. Sobczak, A. Kudyba, G. Bruzda, and R. Nowak, Foundry Research Institute, 73 Zakopianska Str., 30-418 Krakow, Poland; N. Sobczak, Foundry Research Institute, 73 Zakopianska Str., 30-418 Krakow, Poland; and Institute of Precision Mechanics, 3 Duchnicka Str., 01-796 Warsaw, Poland; and K. Pietrzak and M. Chmielewski, Institute of Electronic Materials Technology, 133 Wolczynska Str., 01-919 Warsaw, Poland; and W. Strupiński, Politechnika Warszawska Wydział Fizyki, 75 Koszykowa Str., 00-662 Warsaw, Poland. Contact e-mail: marta.homa@iod.krakow.pl. in electronic and automotive industry, aerospace, fuel cells, etc. (Ref 1-6). While some enhancement of thermal properties of MMCs with carbon nanotubes seem to be attainable (Ref 7), a large-scale manufacturing of graphene reinforced MMCs is accompanied by still difficult-to-overcome problems, mainly related with the occurrence of the agglomeration of graphene phase due to electrostatic forces (Ref 8) and a weak interfacial bonding between the graphene flakes and metal matrix (Ref 9). A microelectronic packaging is another possible graphene application field, e.g., as transparent conducting layers or fillers in solder alloys that could reduce the cost or energy consumption and improve the reliability of electronic components (Ref 10-13). For all above-mentioned graphene-based solutions, information on interaction between liquid metals and graphenecoated materials, particularly wetting behavior and interfaces, is of a great practical importance for different liquid-assisted processes.

To our best knowledge, reported literature data on wetting properties of graphene-coated surfaces are limited to water and organic liquids showing the wetting behavior and the contact angle values similar to those of uncoated surfaces (Ref 14-18). This phenomenon, described by Rafiee et al. (Ref 19) as the graphene wetting transparency, has been also theoretically predicted by molecular dynamic simulations (Ref 19) and confirmed experimentally for different low-temperature liquids and various types of substrate materials $[\mathrm{Cu}$ foil (Ref 16), 
HOPG (Ref 17), graphite (Ref 17), Si (Ref 19)]. However, there is no available report on wetting behavior of high-temperature liquids on graphene-coated materials. The first attempt to investigate wetting properties of a liquid metal on graphene has been done by Sobczak et al. (Ref 20) by using liquid tin and graphene-coated $\mathrm{Cu}$ substrate $\left(\mathrm{C}_{\mathrm{Gn}} / \mathrm{Cu}\right)$. It was demonstrated that the presence of graphene layer on the $\mathrm{Cu}$ substrate delays the wetting process, as compared to the uncoated $\mathrm{Cu}$ substrate, while wetting behavior of liquid tin on the $\mathrm{C}_{\mathrm{Gn}} / \mathrm{Cu}$ substrate was found to be very similar to that on uncoated pure $\mathrm{Cu}$. Thus, the results obtained in Ref 20 did not clearly confirm the existence of graphene wetting transparency effect with liquid tin as it was previously reported for inorganic liquids or water in Ref 14-19. On the other hand, the results of structural characterization performed by Sobczak et al. (Ref 20) on crosssectioned solidified sessile drop couples showed the presence of interfacial intermetallic compound layer. It was proposed that this layer can be formed due to the mass transfer between the $\mathrm{Cu}$ substrate and liquid $\mathrm{Sn}$, i.e., under conditions when the graphene layer does not play a role of a barrier for $\mathrm{Sn}$ atoms. The above contradictions were explained by the possible reconstruction of graphene layer during a high-temperature interaction with liquid tin leading to the formation of structural discontinuities through which liquid tin reacts with the substrate and, consequently, the graphene wetting transparency effect is masked or hindered (Ref 20).

This paper reports the results of in situ observation of hightemperature behavior of molten $\mathrm{Cu}$ drops in contact with graphene layer deposited on $\mathrm{SiC}$ single-crystalline substrate using the same testing procedure and experimental facility as those previously used for the $\mathrm{Sn} / \mathrm{C}_{\mathrm{Gn}} / \mathrm{Cu}$ system in Ref 20 .

\section{Experimental}

\subsection{Materials}

The materials used were $\mathrm{Cu}$ of $99.99 \%$ purity (Hutmen S.A. Company, Poland) and graphene-coated silicon carbide singlecrystalline substrate $\left(\mathrm{C}_{\mathrm{Gn}} / \mathrm{SiC}^{\mathrm{sc}}\right)$ produced by the Institute of Electronic Materials Technology (Warsaw, Poland). The graphene layer was produced by chemical vapor deposition (CVD) process on conductive $\mathrm{SiC}$ substrates described in detail earlier (Ref 21). The produced $\mathrm{C}_{\mathrm{Gn}} / \mathrm{SiC}^{\mathrm{sc}}$ sample was kept in sealed capsules in order to eliminate the risk of contamination.

\subsection{Methods}

The sessile drop (SD) method (Ref 22, 23) was applied to investigate a high-temperature wetting behavior of molten $\mathrm{Cu}$ on $\mathrm{C}_{\mathrm{Gn}} / \mathrm{SiC}^{\mathrm{sc}}$ substrate using an experimental complex described in details in Ref 23. Directly before loading into vacuum chamber, the graphene-coated $\mathrm{SiC}$ substrate was taken from a sealed capsule and placed on alumina support located inside tantalum-resistant heater of vacuum chamber. In order to avoid the effects of native oxide film on metal sample as well as to eliminate the impact of heating history on wetting behavior, the research was performed under ultrahigh vacuum (UHV) conditions using a non-contact heating of a metal and a substrate combined with capillary purification (cp) as described in the works (Ref 22, 23). For this purpose, also directly before loading into vacuum chamber, the $\mathrm{Cu}$ sample was cleaned mechanically and ultrasonically in isopropanol and placed inside a ceramic capillary (made of either graphite or alumina) positioned above the $\mathrm{C}_{\mathrm{Gn}} / \mathrm{SiC}^{\mathrm{sc}}$ substrate. After evacuation of gases and achieving the vacuum of about $p=2 \times 10^{-5}$ mbar by means of a turbomolecular pump, the setup was heated to the test temperature of $1100{ }^{\circ} \mathrm{C}$ with a rate of $10{ }^{\circ} \mathrm{C} / \mathrm{min}$ and then the $\mathrm{Cu}$ drops were deposited on the substrate.

During the whole course of wettability experiments, the types and amounts of residual gases in the vacuum chamber were monitored in real-time using Pfeiffer Prisma QMS200 quadrupole device, while the images of the drop/substrate couple were recorded by MC1310 high-speed high-resolution camera with a rate of 50 frames per second. The collected images were used to estimate the contact angle values by ASTRA2 software [IENI-CNR, Italy (Ref 24, 25)]. The software allows determining the contact angle on left and on right sides of a drop by an automatic image analysis with systematic uncertainty less than $\pm 2^{\circ}$. The collected images were also used for making movies of the test performed at high temperature (see SUPPLEMENTARY 1-3). After each wettability test, the system was cooled with a rate of about $20^{\circ} \mathrm{C} /$ min.

The structural characterization was performed on both the starting materials and the solidified sessile drop $\mathrm{Cu} / \mathrm{C}_{\mathrm{Gn}} / \mathrm{SiC}$ couples using the following techniques:

(1) Scanning probe microscopy (SPM) combined with Raman spectroscopy using NTEGRA Spectra system (NTMDT Europe). The Raman spectra were taken under ambient conditions using an diode pumped solid-state laser with a wavelength of $473 \mathrm{~nm}$. The incident laser power was $50 \mathrm{~mW}$, the spot size $\sim 1 \mu \mathrm{m}$ in diameter and the exposure time $30 \mathrm{~s}$.

(2) Scanning electron microscopy (SEM) using TM3000 Hitachi device equipped with energy-dispersive $\mathrm{X}$-ray spectroscopy (EDS) analyzer.

\section{Results and Discussion}

The results of SPM analysis of the $\mathrm{C}_{\mathrm{Gn}} / \mathrm{SiC}$ substrate showed a characteristic terraced structure on the surface of single $\mathrm{SiC}$ crystal (that was recognized as the effect of polishing) (Fig. 1a). The obtained representative Raman spectrum of graphene produced on $\mathrm{SiC}(001)$ was characterized by the presence of peaks related to $\mathrm{SiC}\left(1300-1750 \mathrm{~cm}^{-1}\right)$ and three major bands of graphene, namely D, G and 2D (Fig. 1b). Their Raman shifts for a laser wavelength of $473 \mathrm{~nm}$ are 1414 , 1603 and $2753 \mathrm{~cm}^{-1}$, respectively. A full width at half maximum (FWHM) of 2D peak with a value of about $58 \mathrm{~cm}^{-1}$ indicates that the tested graphene is a two-layer product (Ref 26). The lower intensity of D peak as compared to peaks $\mathrm{G}$ and $2 \mathrm{D}$ proves that graphene is only mildly defective. The measurement repeated several times in different places on the substrate, both on the surface and on the edges of $\mathrm{SiC}$ terraces, showed a spectrum typical of graphene, which confirms the continuity of mildly defective layer of $\mathrm{C}_{\mathrm{Gn}}$.

\subsection{Wettability Tests with Alumina Capillary}

The first wettability test was performed with an alumina capillary using a continuous contact of the $\mathrm{Cu}$ drop with the 


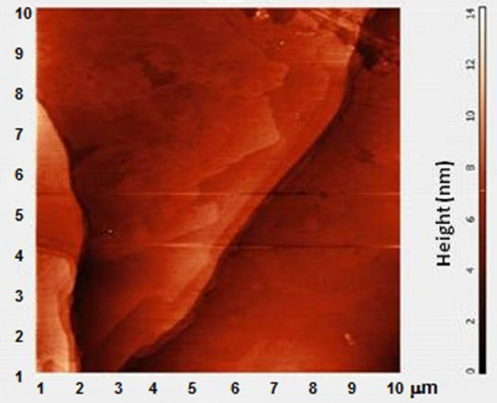

(a)

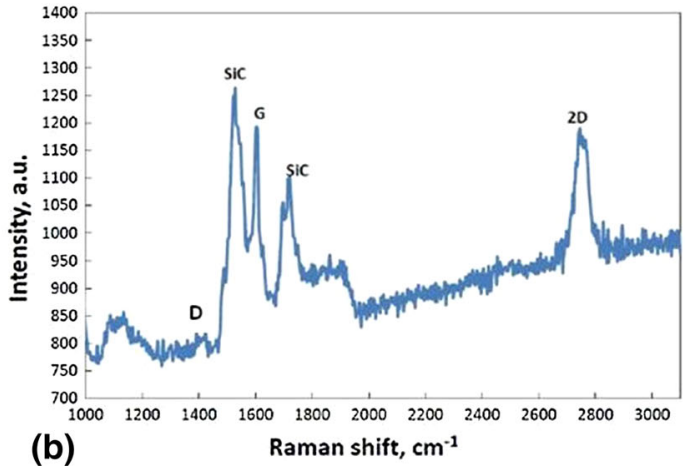

(b) Raman shift, $\mathrm{cm}^{-1}$

Fig. 1 A surface characterization of graphene layer obtained on SiC single crystal: (a) SPM image of the graphene on 4H-SiC (0001) substrate; (b) a Raman spectrum

capillary during drop deposition on the substrate (SUPPLEMENT \#1), i.e., after squeezing the $\mathrm{Cu}$ drop, the capillary was moved down to establish a contact between the drop and the substrate. Subsequently, the capillary was moved up in order to detach it from the drop. However, rising the capillary was accompanied with lifting the whole drop/substrate couple because the drop was well bonded to the substrate. A similar behavior and problems with the $\mathrm{Cu}$ drop detachment from the capillary were observed with uncoated $\mathrm{SiC}$ single-crystal substrate. On the contrary, when the same test was performed with graphite substrate, the $\mathrm{Cu}$ drop did not establish a good bonding with graphite since every rise in the capillary after the drop deposition caused a complete detachment of the drop from the substrate and no residual metal was observed on the substrate surface. The effect of the substrate material on dissimilar behavior of the $\mathrm{Cu}$ drop during rising of the capillary, when the drop is connected with both the capillary and the substrate, is in a good agreement with existing knowledge. The $\mathrm{Cu} / \mathrm{C}$ system is recognized as non-wetting and non-reactive; thus, adhesion between $\mathrm{Cu}$ and all carbon materials is week, independently on carbon allotropic form (Ref 27). On the contrary, a strong interaction between $\mathrm{Cu}$ and $\mathrm{SiC}$ (Ref 28-33) was reported, hence substantial adhesion between the $\mathrm{Cu}$ drop and the $\mathrm{SiC}$ substrate is obvious. The above observations demonstrate the similarity of the $\mathrm{Cu}$ drop behavior with graphene-coated and graphene-free $\mathrm{SiC}$ substrates, thus suggesting that under conditions of this study, the graphene layer is transparent for liquid $\mathrm{Cu}$.

In the same test after the first attempt, the second lowering and re-raising the capillary resulted in a successful drop detachment but also in the appearance and floating of large solid-like fragment on the drop surface (Fig. 2). During holding at the test temperature, this fragment was moved to the top of the drop and settled in a tilled position on the capillary resulting in the deformation of initially symmetrical drop. This in turn made difficult reliable measurements of the contact angles formed between the $\mathrm{Cu}$ drop and the substrate $(t=0 \mathrm{~min}$, $\theta_{\mathrm{av}}=112^{\circ} ; t=30 \mathrm{~min}, \theta_{\mathrm{av}}=82.6^{\circ}$ ).

After deposition on substrate, the $\mathrm{Cu}$ drop formed average value contact angle of $\theta_{\mathrm{av}}=112^{\circ}\left(\theta<90^{\circ}\right)$. Contact angle was not stable with time and started decreasing to form the final value of $\theta_{\mathrm{av}}=82.6^{\circ}$ after $30 \mathrm{~min}$.

The SEM top view observations of the solidified drop (Fig. 3a and b) revealed a large round pancake-like fragment dark gray in color. Figure 3(c) shows a higher magnification of rectangle marked in Fig. 3(b) with EDS analysis of chemical composition in three well-distinguished regions (in at.\%): 1 - dark region enriched in carbon and containing only $1.4 \%$ $\mathrm{Si}$; 2-bright region rich in $\mathrm{Cu}$ and containing $5.7 \% \mathrm{Si}$; 3 - dark region, also enriched in carbon, corresponding to the drop-side surface of wrapped "pancake" fragment. More detailed EDS analysis of the wrapped region (Fig. 3d) displays mainly carbon $(94.7 \%$ in its dark-black area, $88.0-89.0 \%$ in its gray area and $76.9 \%$ in its white-gray area), small amount of $\mathrm{Si}$ $(1.1-2.3 \%)$ and residual $\mathrm{Cu}(4.2-20.8 \%)$ coming from the drop detachment. The results of SEM + EDS characterizations suggest that the pancake-like fragment presents the graphene layer detached from the substrate along the substrate/graphene interface and subsequently transferred on the drop surface. Since the diameter of the graphene fragment is comparable to that of the drop/substrate contact area during the first rising of the capillary (about $2 \mathrm{~mm}$ ), one may conclude that the first upand-down movement of the substrate causes weakening the graphene layer along the contact line. After that the cutting of
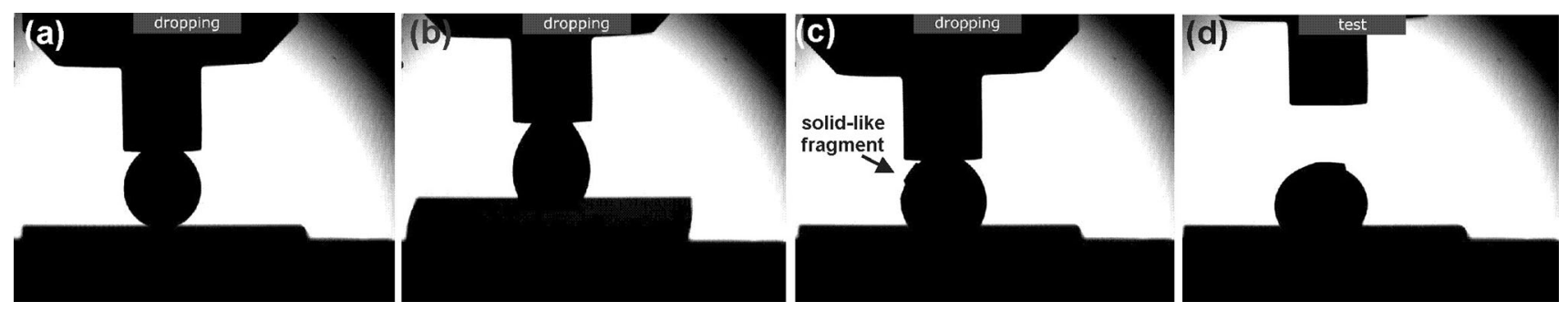

Fig. 2 The wetting behavior of $\mathrm{Cu}$ drop during wettability test on graphene-coated $\mathrm{SiC}$ substrate at $1100{ }^{\circ} \mathrm{C}$ (wettability test with alumina capillary): (a) the deposition of the $\mathrm{Cu}$ drop; (b) rising of $\mathrm{C}_{\mathrm{Gn}} / \mathrm{SiC}$ substrate; (c) detachment large solid-like fragment, (d) the end of the test after $t=30 \mathrm{~min}$ 

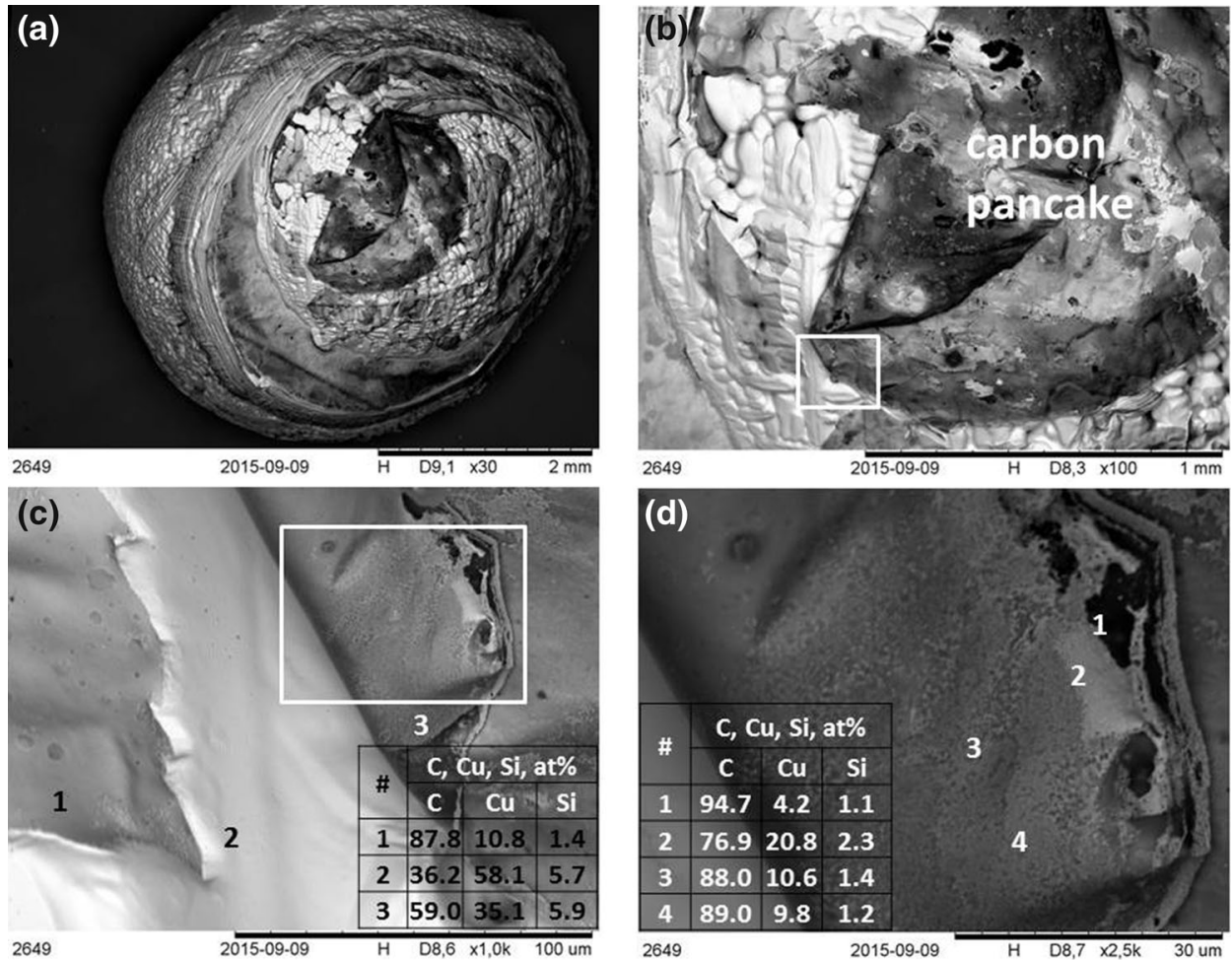

Fig. 3 (a)-(c) Top view SEM images of the $\mathrm{Cu}$ drop surface after interaction with the graphene-coated $\mathrm{SiC}$ substrate at $1100{ }^{\circ} \mathrm{C}$ (the wettability test with alumina capillary): (c) and (d) show magnified area of (a) (marked by rectangle) together with corresponding EDS analysis of distribution of $\mathrm{Cu}, \mathrm{C}$ and $\mathrm{Si}$ in points $1-4$

graphene layer takes place upon the second substrate lifting and final drop separation from the substrate.

Several combined factors contribute to this phenomenon, e.g., stresses generated from capillary forces at the triple line, the gravitation force, a substrate deformation under acting forces, local defects formed due to the rearrangement of $\mathrm{C}$ atoms in the graphene layer in the presence of liquid metal, as well as due to a higher mobility of atoms at high temperature. Moreover, despite a very low solubility of carbon in liquid $\mathrm{Cu}$ at the test temperature $[\sim 1$ at. ppm (Ref 34)], it might be sufficient to create discontinuities in the graphene layer and thus to stimulate its cracking in its most loaded and weakest region corresponding to the contact line.

\subsection{Wettability Tests with Graphite Capillary}

By taking into account aforementioned considerations, the next wettability tests were performed using a graphite capillary in order to reduce the effect of carbon dissolution in $\mathrm{Cu}$. Based on the $\mathrm{Cu}-\mathrm{C}$ phase diagram [Fig. 4 (Ref 35)], it was assumed that slow heating of $\mathrm{Cu}$ sample in the graphite capillary to the test temperature should cause its saturation with carbon while after melting, the $\mathrm{Cu}$ drop might be oversaturated with $\mathrm{C}$. This assumption comes from the peritectic type of the $\mathrm{Cu}-\mathrm{C}$ system showing that at temperature of peritectic reaction, the solubility of carbon in solid state is much higher as compared to that in liquid state [1.0-7.4 at. ppm (Ref 34,35$)$ and 10-370 at. ppm (Ref 36, 37), respectively]. The results of recent research (Ref 37) confirmed the maximum solid-state solubility of $\mathrm{C}$ in $\mathrm{Cu}$ as 10 at. ppm.

During tests with the graphite capillary, two $\mathrm{Cu}$ drops were gently deposited on the graphene-coated surface of $\mathrm{SiC}^{\mathrm{sc}}$

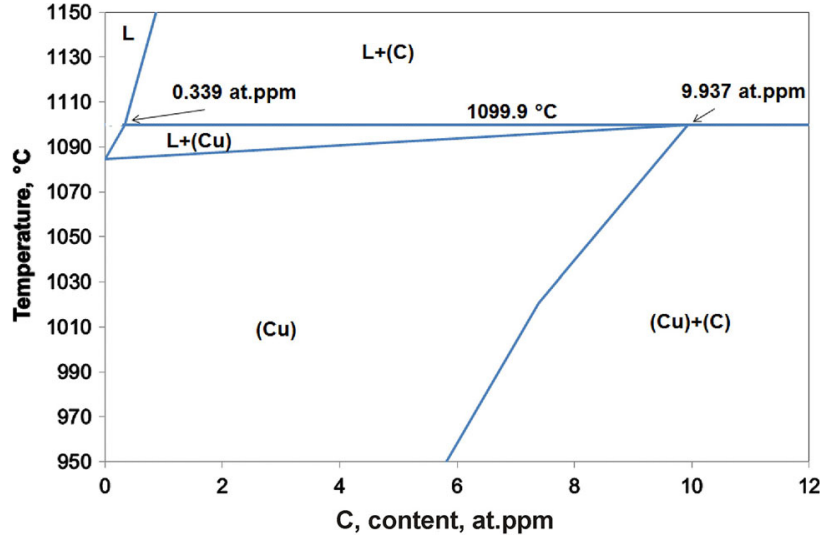

Fig. 4 Cu-C phase diagram (Ref 36)

substrate at $1100{ }^{\circ} \mathrm{C}$ as it is shown schematically in Fig. 5. Contrary to previous test with alumina capillary, both drops were easily detached from the graphite immediately after squeezing the molten metal through a hole in the capillary. The detailed analysis of collected images and the corresponding movie (see SUPPLEMENT \#2) revealed that within the first second after drop squeezing and deposition (Fig. 6a, b, c, d, e, and $\mathrm{f}$ ), the first drop only touched the $\mathrm{C}_{\mathrm{Gn}} / \mathrm{SiC}^{\mathrm{sc}}$ substrate (Fig. 6b) and then immediately rolled like a ball to another position (Fig. 6c, d, e, and f). After that the drop moved slightly back, and finally it settled near the edge of the substrate, forming asymmetric shape (Fig. $6 \mathrm{~g}$ and $\mathrm{h}$ ). During the drop rolling, the change of substrate position and its slight rotation on the alumina support were also noted (as marked by arrows in Fig. $6 \mathrm{~b}, \mathrm{c}, \mathrm{d}, \mathrm{e}, \mathrm{f}$, and g) 


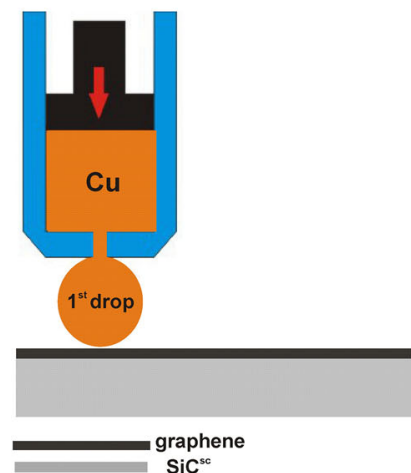

(a)

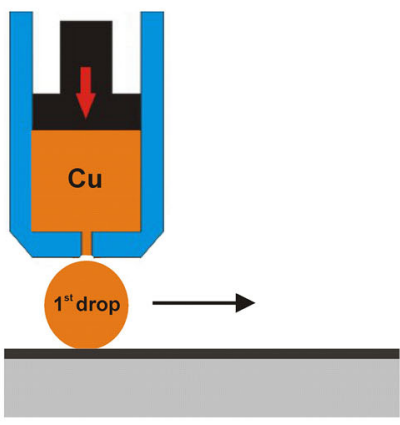

(b)

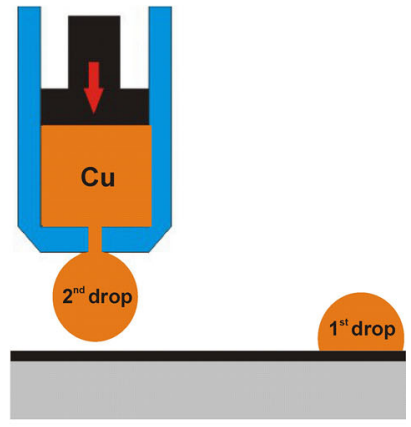

(c)

Fig. 5 A schematic presentation of the sessile drop wettability test of liquid $\mathrm{Cu}$ on graphene-coated $\mathrm{SiC}$ single-crystalline substrate using the graphite capillary: (a) squeezing of liquid $\mathrm{Cu}$ through a hole in the capillary; (b) a gentle deposition of the first $\mathrm{Cu}$ drop; (c) a deposition of the second $\mathrm{Cu}$ drop after movement of the first drop to the another side of the substrate
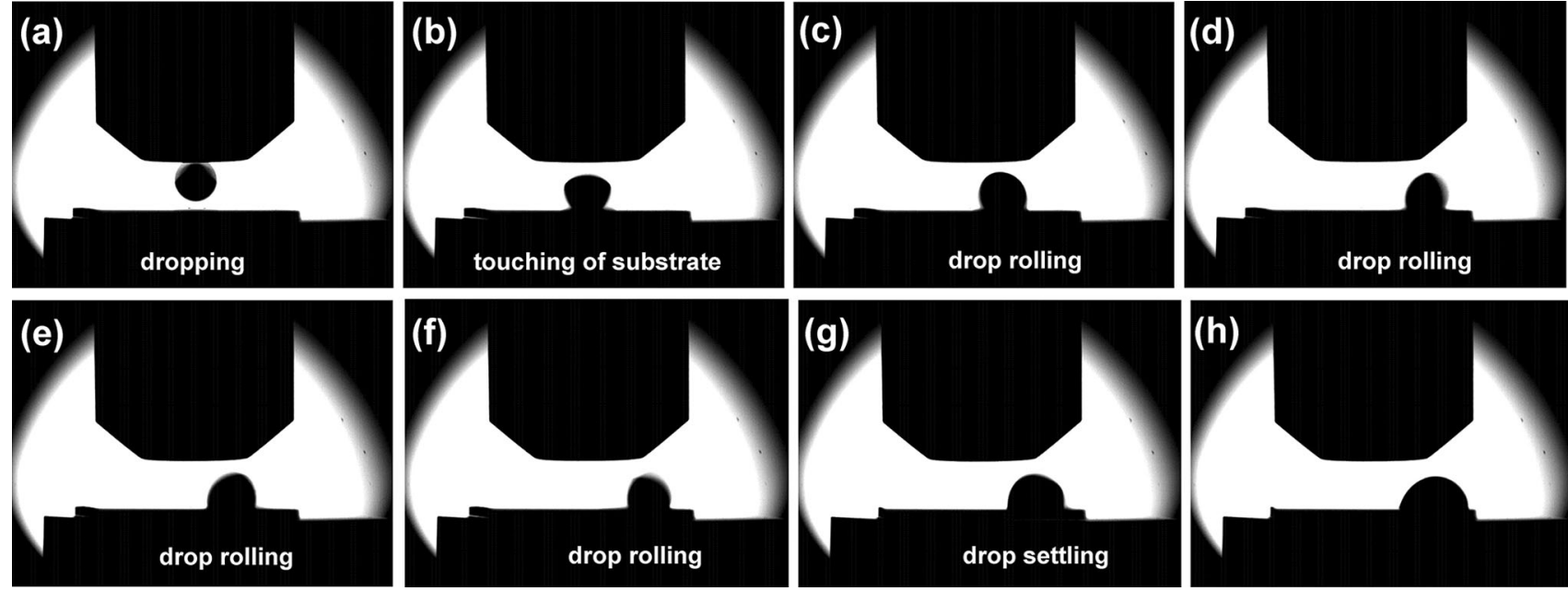

Fig. 6 Images of the first $\mathrm{Cu}$ drop recorded with the high-speed high-resolution camera during most representative moments of the first second of the test with the graphite capillary: (a) the start of metal dropping from the capillary-the first drop; (b) touching of the substrate; (c)-(f) the drop rolling; ( $\mathrm{g}$ ) the drop settling; (h) the beginning of test—-before second drop squeezing; the arrows indicate the substrate displacement

For the second $\mathrm{Cu}$ drop that was dispensed on the same substrate after about $4 \mathrm{~s}$ from squeezing the first drop, different wetting behavior was observed (Fig. 7). After the gentle deposition of the second drop on the substrate, rising the capillary caused a short time lifting of the $\mathrm{C}_{\mathrm{Gn}} / \mathrm{SiC}$ substrate (Fig. 7a, b, and c). Then the substrate fell down, resulting in the separation of the drop from the capillary, and finally, the drop was settled on the substrate forming a spherical shape (Fig. 7d) without changing its position till the end of the test (Fig. 7f, g, and $\mathrm{h}$ ). However, contrary to the first drop, a further interaction of the second drop with the substrate was accompanied by the formation of thick interfacial reaction product and the change in the drop size (Fig. 7f). During holding the system at the test temperature for $30 \mathrm{~min}$, notable increase in the volume of reactively formed interfacial region took place at the expense of the decrease in the drop size.

Figure 8(a), (b) and (c) shows the change in contact angle $(\theta)$ with time during wettability test of two $\mathrm{Cu}$ drops on the $\mathrm{C}_{\mathrm{Gn}} / \mathrm{SiC}^{\mathrm{sc}}$ substrate using the graphite capillary. The first $\mathrm{Cu}$ drop did not wet the substrate $\left(\theta>90^{\circ}\right)$ forming the left and the right contact angles of the same value $\left(121^{\circ}\right)$ at the first moment of contact with the substrate after squeezing from the capillary (Fig. 8a and b). After settling near the edge of the substrate in about $0.15 \mathrm{~s}$, non-wetting-to-wetting transition took place $\left(\theta<90^{\circ}\right)$ and the $\mathrm{Cu}$ drop formed the right and left contact angles of different values $\theta_{\mathrm{R}}=86^{\circ}$ and $\theta_{\mathrm{L}}=70^{\circ}$, respectively (Fig. 8b). Whereas the right contact angle was stable with time, the left contact angle started decreasing to form the final value of $\theta_{\mathrm{L}}=19^{\circ}$ after $30 \mathrm{~min}$. Average value $\theta_{\mathrm{av}}=\left(\theta_{\mathrm{R}}+\theta_{\mathrm{L}}\right) / 2=52^{\circ}$.

The second $\mathrm{Cu}$ drop also did not wet the substrate immediately after its deposition, forming similar right and left contact angles to that of the first drop $\left(123^{\circ}\right)$. However, both angles rapidly decreased in $17 \mathrm{~min}$ to the same value of $\theta=23^{\circ}$. A further isothermal heating resulted in the change of the drop shape accompanied with the formation of dissimilar values of right and left contact angle and their increase with time to form an average value of $65^{\circ}$ after $30 \mathrm{~min}$.

Besides different wetting behaviors, visual observations of two solidified sessile drops on the same $\mathrm{C}_{\mathrm{Gn}} / \mathrm{SiC}^{\mathrm{sc}}$ substrate (Fig. 9a and b) show their dissimilar shape and size despite of the identical testing conditions. The first drop had an oval shape 

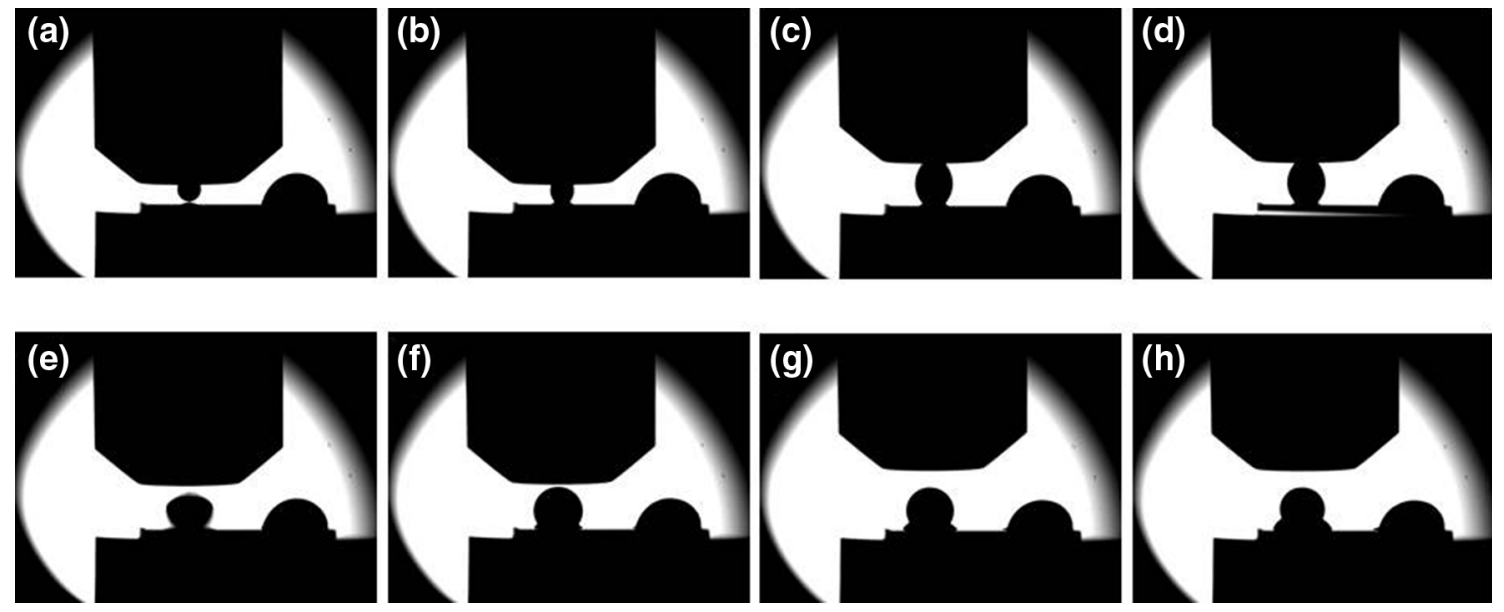

Fig. 7 Wetting behavior of the 2 nd $\mathrm{Cu}$ drop during wettability test on graphene-coated $\mathrm{SiC}$ at $1100{ }^{\circ} \mathrm{C}$ : (a)-(c) drop deposition; (d) substrate lifting together with raising the capillary; (e) separating of the drop from the capillary; (f) 10 min contact; (g) 20 min contact; (h) the end of the test at time $t=30 \mathrm{~min}$
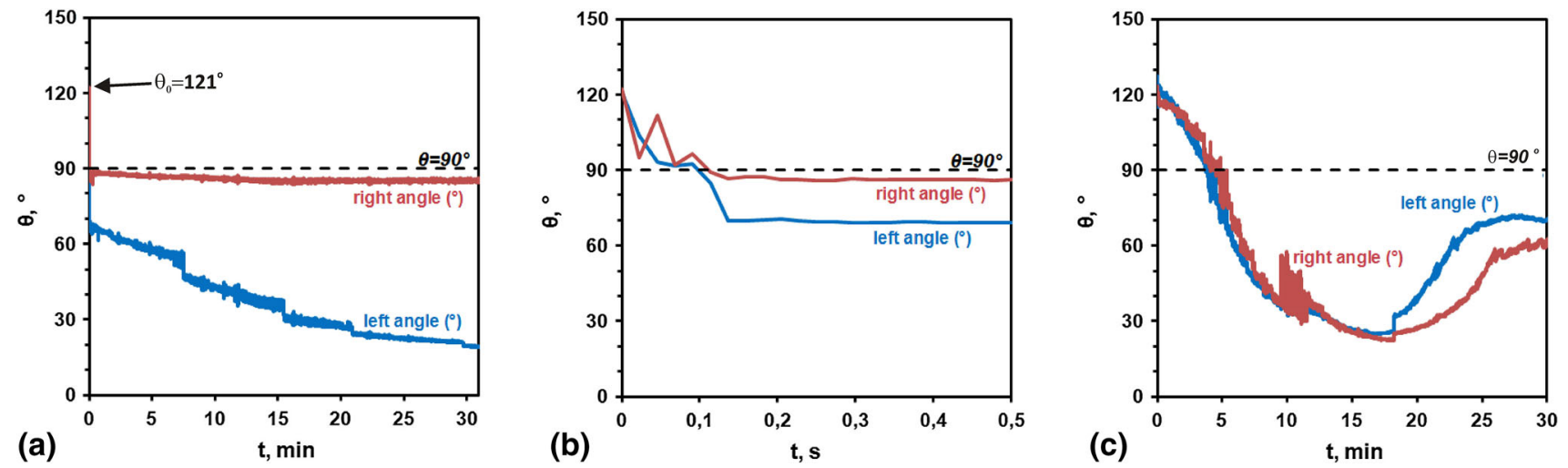

Fig. 8 The wettability kinetics of liquid $\mathrm{Cu}$ on graphene-coated $\mathrm{SiC}^{\mathrm{sc}}$ (the wettability test with the graphite capillary): (a) the first $\mathrm{Cu}$ drop; (b) the magnified part of (a) for $t=0.5 \mathrm{~s}$; (c) the second $\mathrm{Cu}$ drop

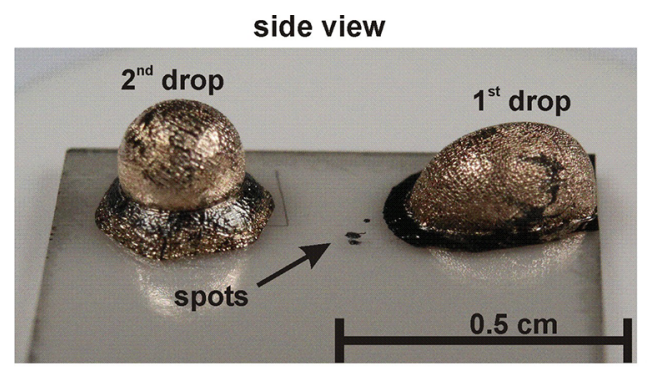

(a)

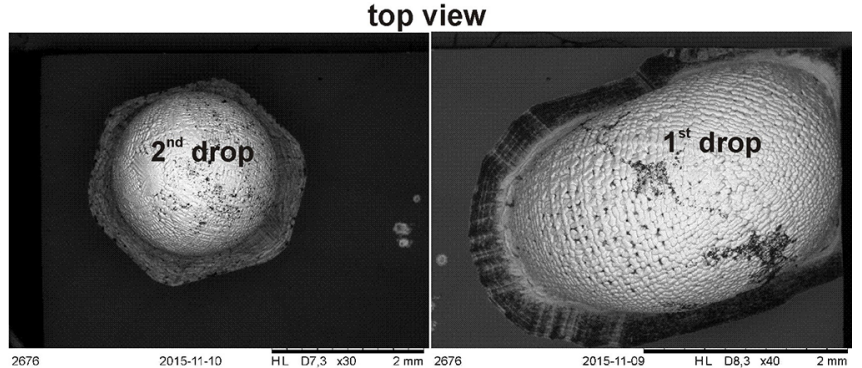

(b)

Fig. 9 Macroview images of solidified sessile drop sample showing the first and second $\mathrm{Cu}$ drops deposited on the graphene-coated SiC substrate (the wettability test with graphite capillary): (a) the side view, (b) the top view

and from the top view it looks larger than the second drop. Around the first drop, a black oval ring is well distinguished. The second drop has a spherical shape, and it is deep-seated on pyramid with hexagonal base. The surfaces of both drops are bright and occasionally covered with black spots. Moreover, similar black spots are found on the $\mathrm{C}_{\mathrm{Gn}} / \mathrm{SiC}$ substrate surface near the first drop.

Figure 10, 11, 12, 13 and 14 show the most representative results of SEM examinations of the sample produced during the wettability test with the graphite capillary. Dark spots com- posed of fine precipitates are well distinguished (Fig. 10a, 11a) on the top views of both solidified drops. They mainly consist of carbon and a small amount of silicon (Fig. 10c, 11c). The side view observations of the first drop revealed many agglomerated dark carbon flakes of different length that reaches the maximum value of $20 \mu \mathrm{m}$ (Fig. 12a and b). Similar regions composed of dark flakes were also detected on the side surface of the second $\mathrm{Cu}$ drop (the results are not shown in the paper). On the surface of the first drop displacement path, the presence of gray areas are well recognized (Fig. 13b). In Fig. 14, similar 

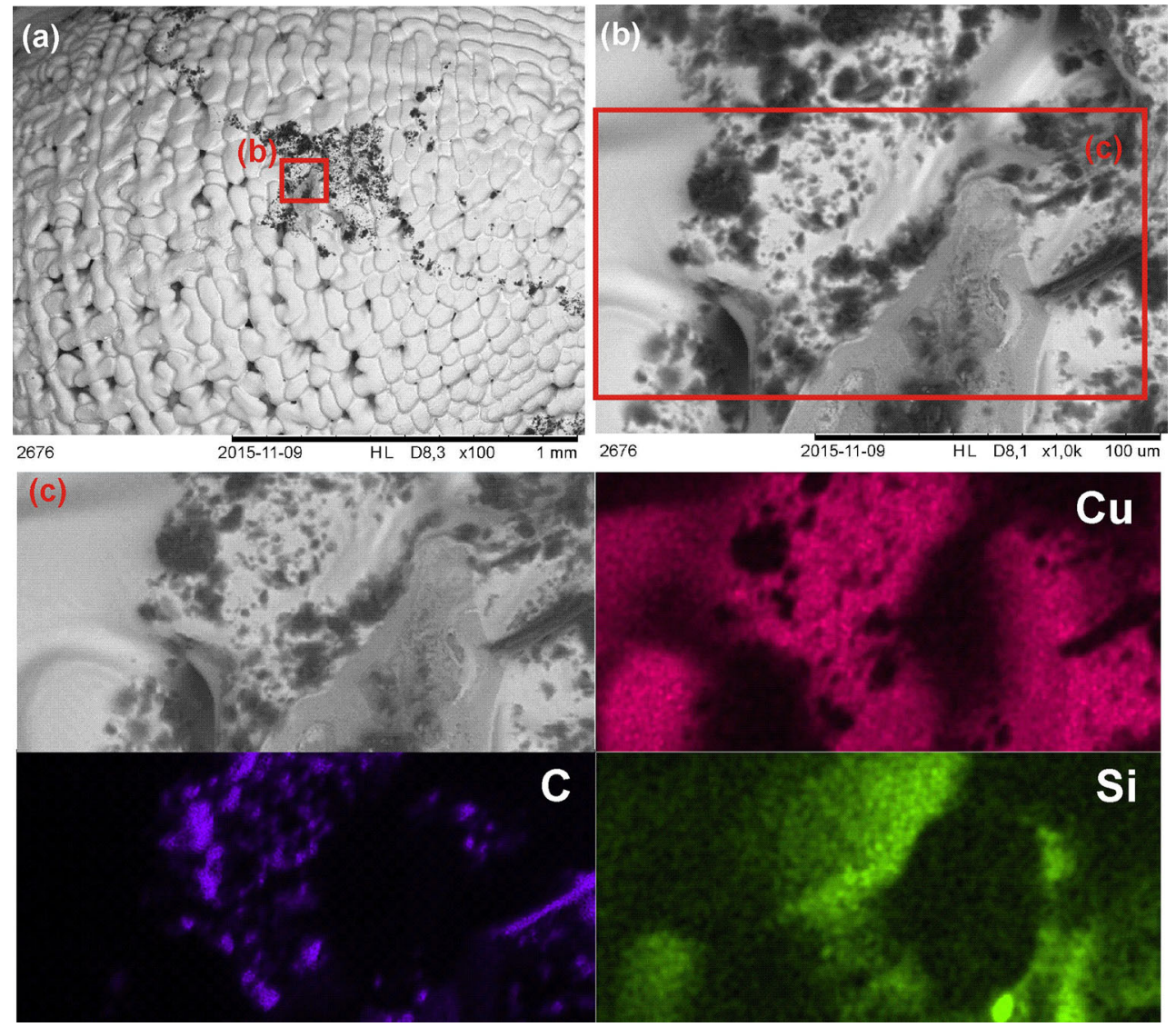

Fig. 10 (a), (b) Top view SEM images of the first $\mathrm{Cu}$ drop surface with marked area in (b); (c) distributions of $\mathrm{Cu}, \mathrm{C}$ and $\mathrm{Si}$

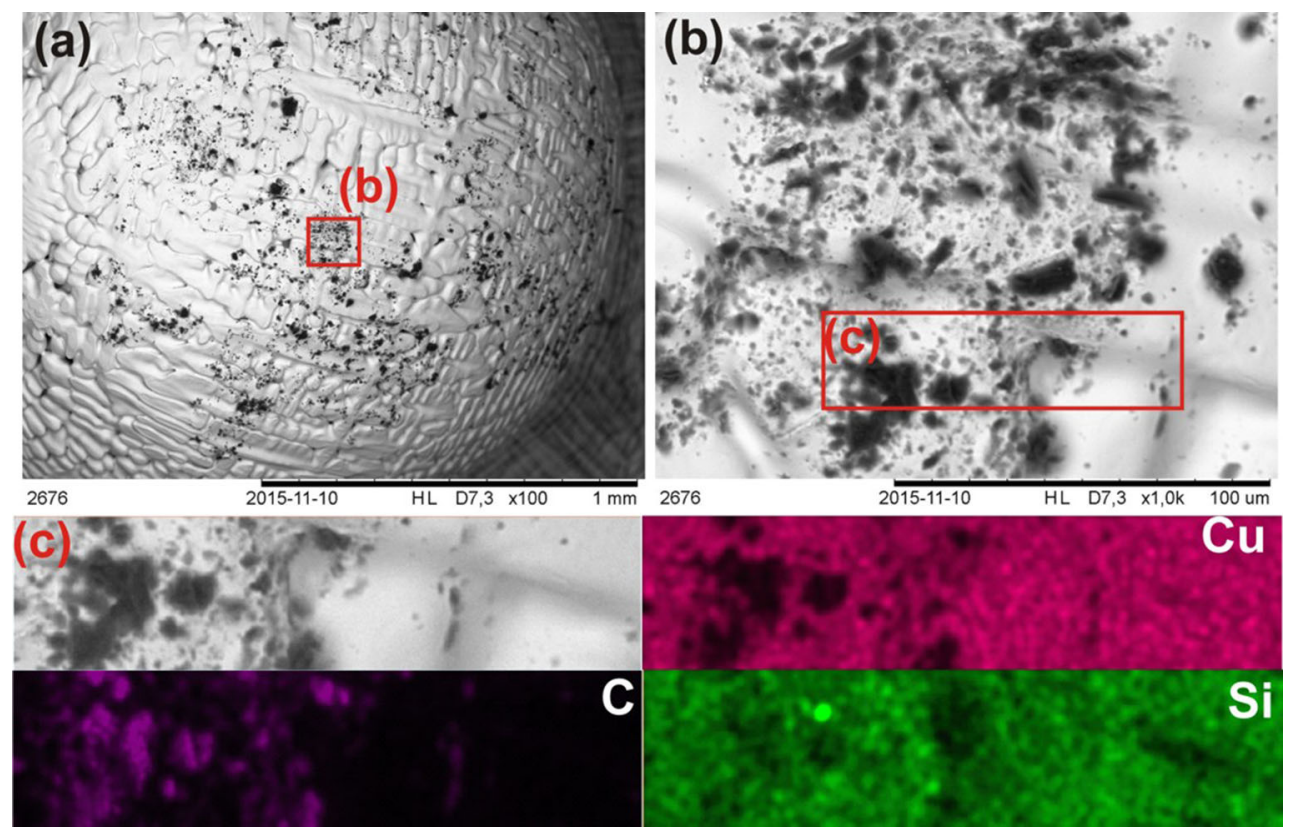

Fig. 11 (a), (b) Top view SEM images of the second $\mathrm{Cu}$ drop with marked area in (b); (c) distribution of $\mathrm{Cu}, \mathrm{C}$ and $\mathrm{Si}$

areas are also observed near the dark spots shown in Fig. 15. The results of EDS analysis point toward a high content of copper in these dark spots.

Figure 15 shows a comparison of Raman spectra taken from different regions of the examined couple after the wettability test. Well-distinguished $\mathrm{G}\left(1610 \mathrm{~cm}^{-1}\right)$ and $2 \mathrm{D}\left(2727 \mathrm{~cm}^{-1}\right)$ peaks of graphene are found on the spectrum taken from the top surface of the first drop (Fig. 16, spectrum (a) and spectrum (b), respectively). These peaks are much smaller on the spectrum taken from the displacement path of first drop. Moreover, 

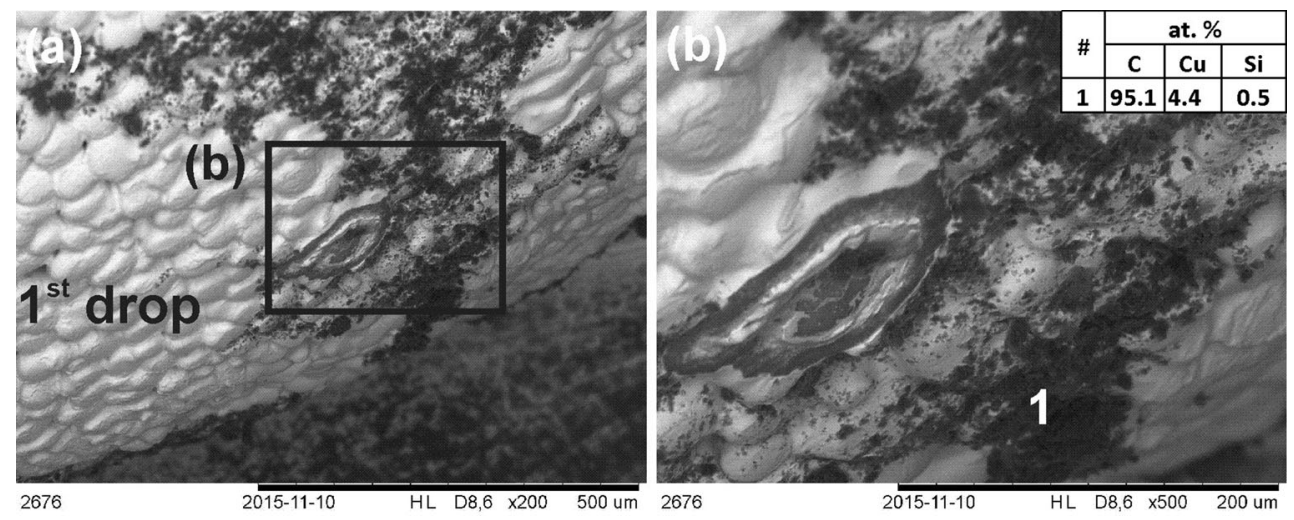

Fig. 12 (a), (b) Side view SEM images of the first $\mathrm{Cu}$ drop surface; (b) marked area in (a) with the results of EDS chemical composition analysis taken from point 1
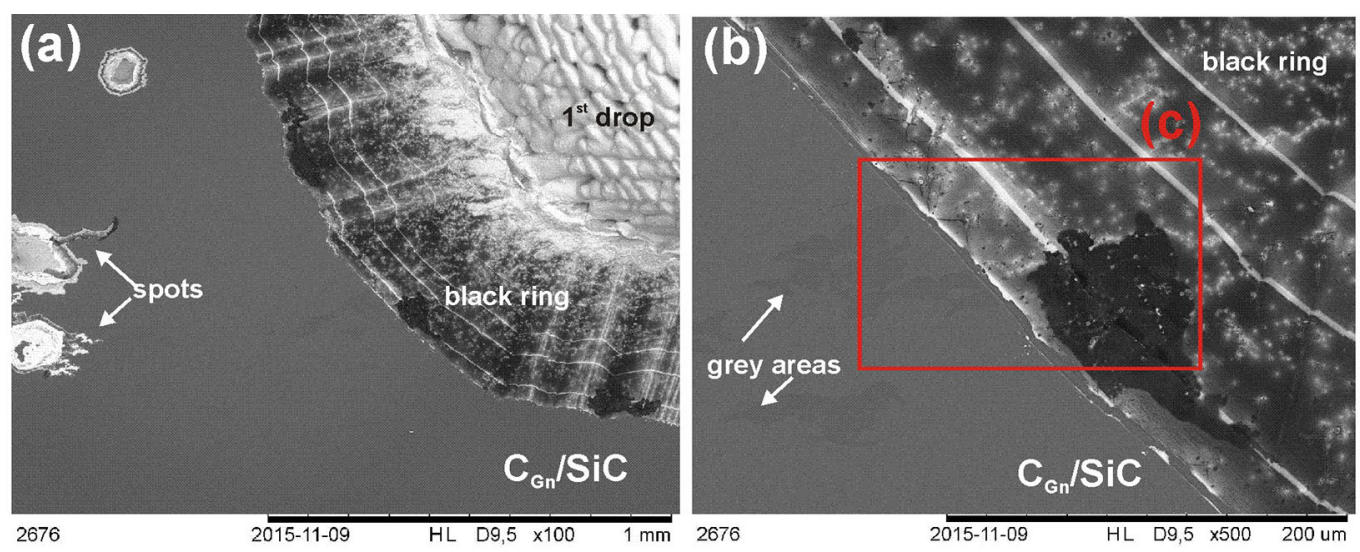

(c)

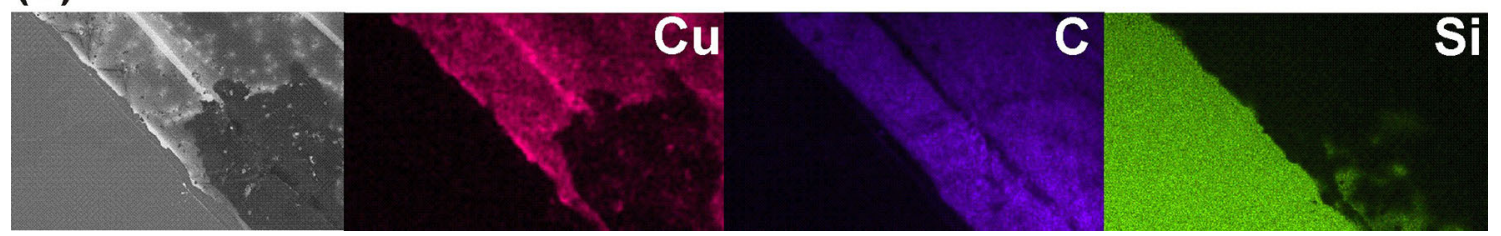

Fig. 13 (a), (b) Top view SEM images of the first drop displacement path near dark ring formed around the first $\mathrm{Cu}$ drop, (c) the distribution of $\mathrm{Cu}, \mathrm{C}$ and $\mathrm{Si}$

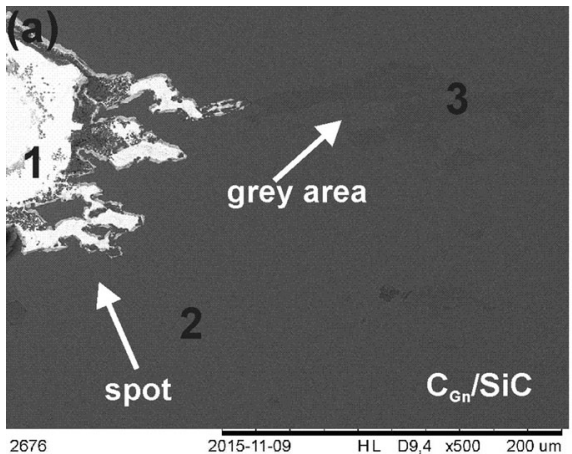

(b)

\begin{tabular}{|c|c|c|c}
\hline \multirow{2}{*}{$\#$} & \multicolumn{3}{|c}{ at. \% } \\
\cline { 2 - 4 } & $\mathrm{C}$ & $\mathrm{Cu}$ & $\mathrm{Si}$ \\
\hline 1 & 95.1 & 4.4 & 0.5 \\
\hline 2 & 57.1 & 1.3 & 41.6 \\
\hline 3 & 56.2 & 0.8 & 43.0 \\
\hline
\end{tabular}

Fig. 14 (a) SEM image of spot visible near the black ring and gray area on the $\mathrm{SGn} / \mathrm{SiC}$ substrate (post-drop rolling region); (b) the results of EDS chemical composition analysis taken from points 1-3 (a)

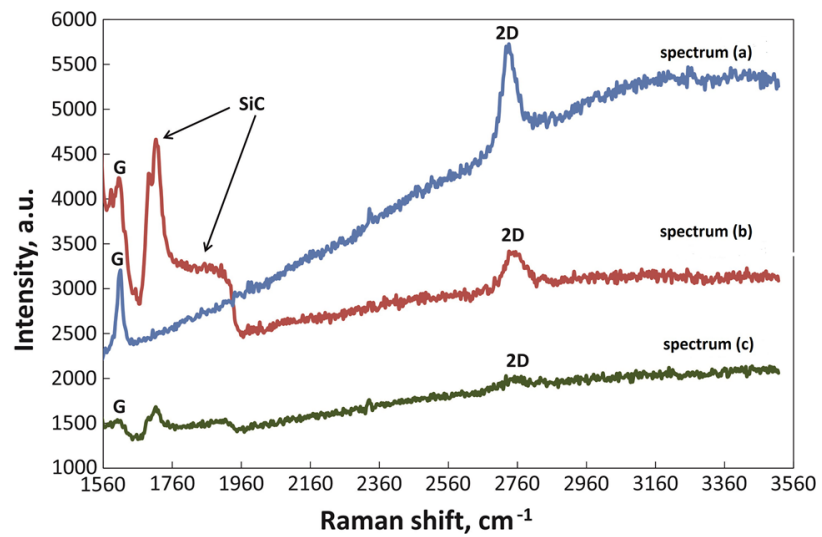

Fig. 15 A comparison of Raman spectra at $437 \mathrm{~nm}$ excitations and the exposure time of $300 \mathrm{~s}$ for: (a) top surface of the first drop; (b) a substrate surface far from the drops; (c) the first drop displacement path on the substrate surface 

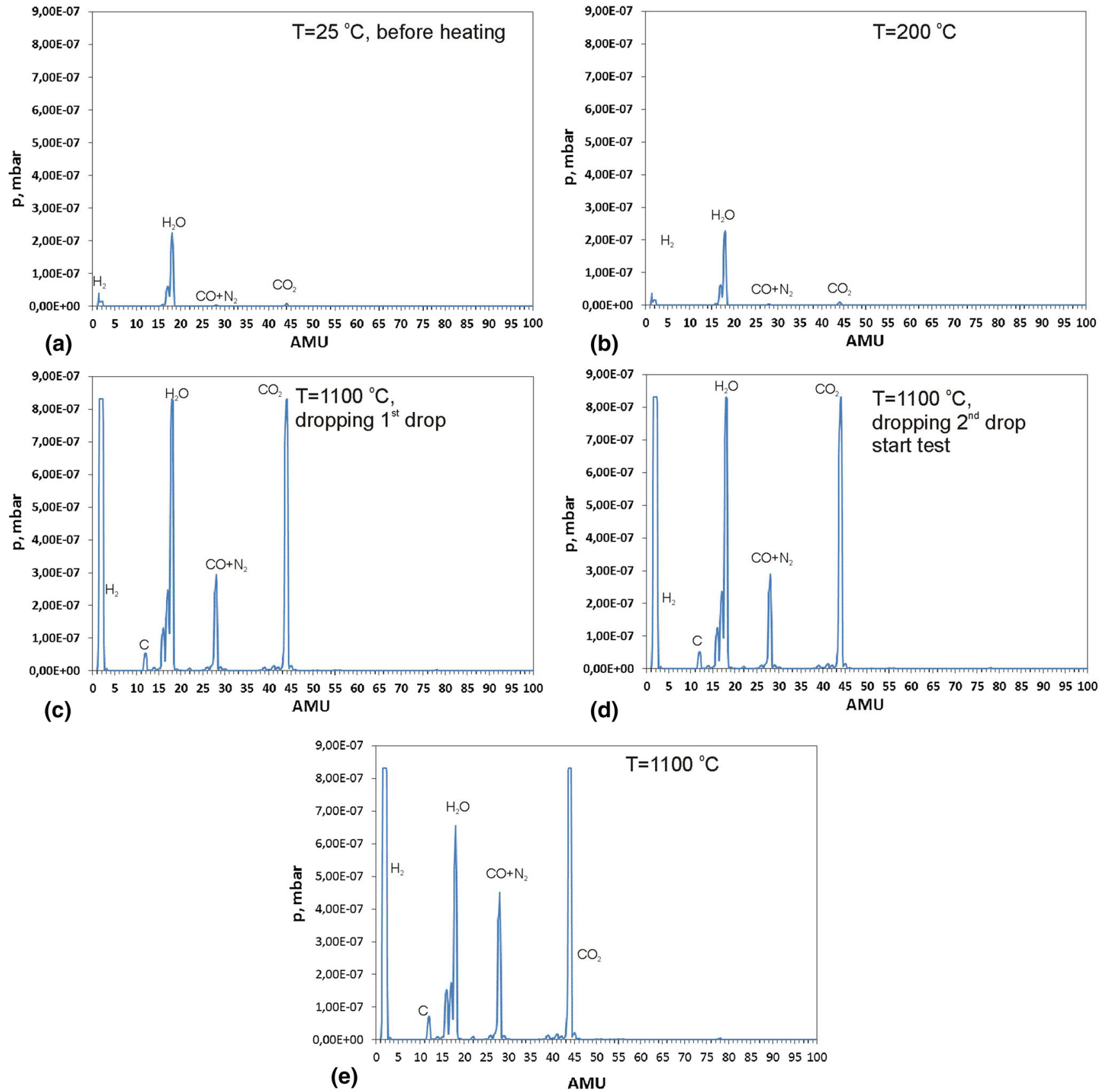

Fig. 16 Partial pressure of residual gases in the test chamber recorded during experiment with $\mathrm{Cu} / \mathrm{CGn} / \mathrm{SiC}$ couples: (a) RT - before heating; (b) $T=200{ }^{\circ} \mathrm{C}$; (c) $T=1100{ }^{\circ} \mathrm{C}-1 \mathrm{st} \mathrm{Cu}$ dropping; (d) $1100{ }^{\circ} \mathrm{C}-2$ nd $\mathrm{Cu}$ dropping; (e) $T=1100{ }^{\circ} \mathrm{C}, t=30$ min (end of the test)

additional peaks corresponding to $\mathrm{SiC}$ appeared, while the FWHM of the 2D peak was $58 \mathrm{~cm}^{-1}$ corresponding to a bilayer graphene structure (Ref 30). A comparison of the above Raman spectra with those taken from graphene-coated substrate surface far from both drops (Fig. 16, spectrum (c)) suggests the $\mathrm{Cu}$ drop displacement on the substrate surface affects its structure and chemistry.

\section{Discussion}

The results of wettability tests of the $\mathrm{Cu} / \mathrm{C}_{\mathrm{Gn}} / \mathrm{SiC}^{\mathrm{sc}}$ couples are collected in Table 1 and compared with previous studies of wetting properties of $\mathrm{Cu}$ in contact with different types of $\mathrm{SiC}$ substrates (Ref 28-30, 32, 33), graphite (Ref 27, 37), glassy-like carbon (Ref 38), $\mathrm{SiO}_{2}$ (Ref 39, 40), and $\mathrm{SiC}$ substrate coated with graphite layer deposited by ion sputtering $\left(\mathrm{C}_{\mathrm{dSiC}}\right)$.

Despite the fact that dissimilar wetting behavior was observed in this research for two $\mathrm{Cu}$ drops on graphene-coated SiC single crystal, both drops showed good wetting with the final contact angles of $\sim 52^{\circ}$ and $\sim 65^{\circ}$, for the 1 st and 2 nd drop, respectively. It is almost three times lower, compared to the contact angle of $157^{\circ}$ we observed with liquid $\mathrm{Cu}$ on graphite under the same testing conditions but using contact heating (ch) procedure, as reported recently in Ref 38) (Table 1 data " $\mathrm{C}_{\mathrm{gr}}$ "). Moreover, additional test, performed in this study 


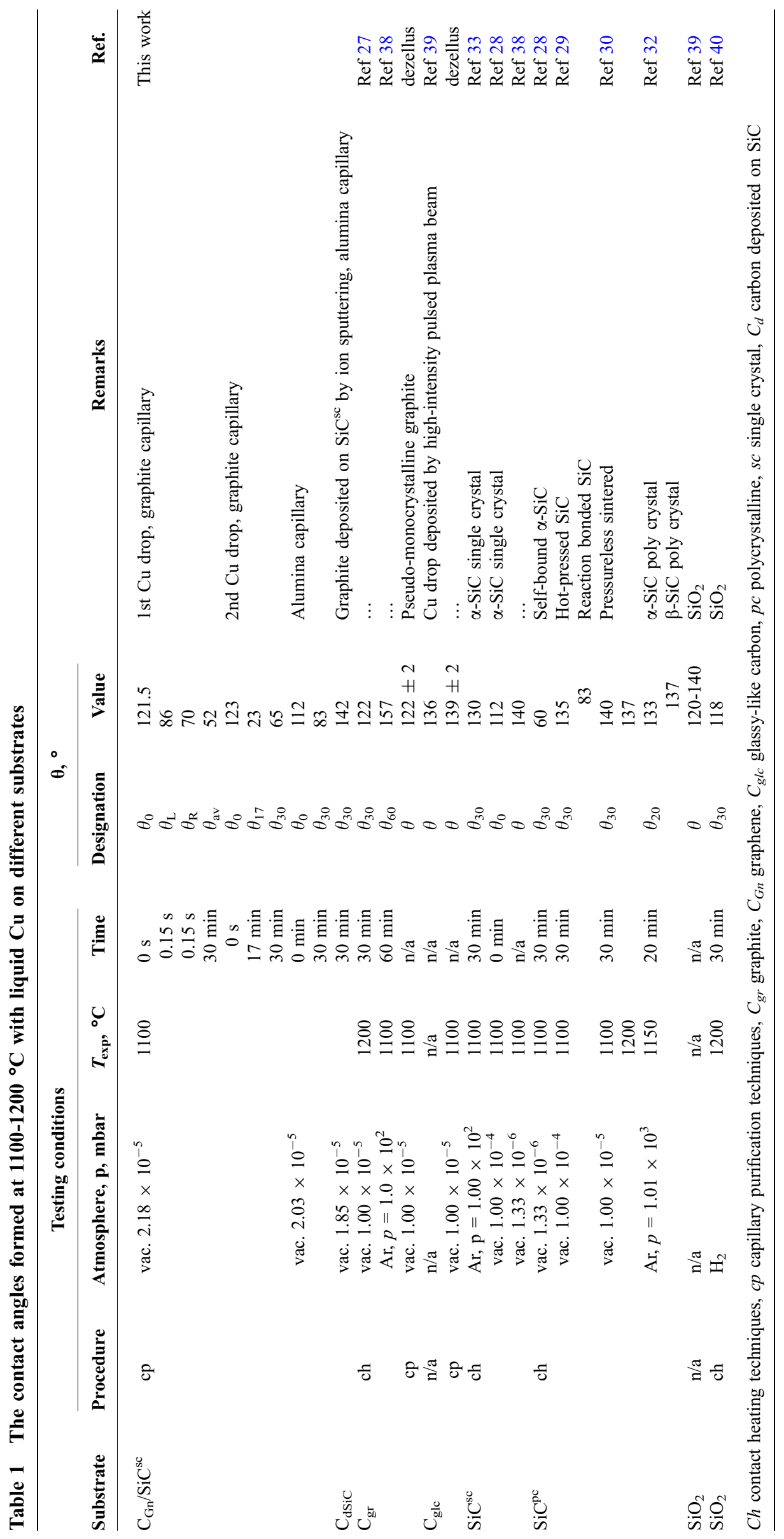


Table 2 Partial pressure of residual gases in the test chamber recorded during experiment with $\mathrm{Cu} / \mathrm{C}_{\mathbf{G n}} / \mathrm{SiC}$ couples

\begin{tabular}{|c|c|c|c|c|c|c|}
\hline $\begin{array}{l}\text { Pressure } \\
T, \text { time }\end{array}$ & $P_{\mathrm{H}_{2}}$, mbar & $P_{\mathrm{H}_{2} \mathrm{O}}$, mbar & $P_{\mathrm{C}}$, mbar & $P_{\mathrm{CO}+\mathrm{N}_{2}}$, mbar & $P_{\mathrm{CO}_{2}}$, mbar & $P_{\text {total }}$, mbar \\
\hline RT & $1.52 \times 10^{-8}$ & $2.25 \times 10^{-7}$ & $5.93 \times 10^{-10}$ & $4.93 \times 10^{-9}$ & $7.63 \times 10^{-9}$ & $1.2 \times 10^{-6}$ \\
\hline $200{ }^{\circ} \mathrm{C}$ & $1.64 \times 10^{-8}$ & $2.28 \times 10^{-7}$ & $7.27 \times 10^{-10}$ & $3.85 \times 10^{-9}$ & $9.43 \times 10^{-9}$ & $1.86 \times 10^{-6}$ \\
\hline $400^{\circ} \mathrm{C}$ & $6.1 \times 10^{-8}$ & $3.29 \times 10^{-7}$ & $1.28 \times 10^{-9}$ & $6.84 \times 10^{-9}$ & $1.65 \times 10^{-8}$ & $3.07 \times 10^{-6}$ \\
\hline $600^{\circ} \mathrm{C}$ & $2.87 \times 10^{-7}$ & $4.21 \times 10^{-7}$ & $3.89 \times 10^{-9}$ & $1.42 \times 10^{-8}$ & $5.89 \times 10^{-8}$ & $4.75 \times 10^{-6}$ \\
\hline $800^{\circ} \mathrm{C}$ & $4.62 \times 10^{-7}$ & $4.72 \times 10^{-7}$ & $7.67 \times 10^{-9}$ & $3.4 \times 10^{-8}$ & $1.24 \times 10^{-7}$ & $6.37 \times 10^{-6}$ \\
\hline $1000^{\circ} \mathrm{C}$ & $8.3 \times 10^{-7}$ & $5.55 \times 10^{-7}$ & $1.48 \times 10^{-8}$ & $7.93 \times 10^{-8}$ & $2.71 \times 10^{-7}$ & $1.16 \times 10^{-5}$ \\
\hline $1100^{\circ} \mathrm{C}, t=0 \mathrm{~s}$ (1st drop) & $8.3 \times 10^{-7}$ & $8.3 \times 10^{-7}$ & $5.33 \times 10^{-8}$ & $2.94 \times 10^{-7}$ & $8.3 \times 10^{-7}$ & $2.28 \times 10^{-5}$ \\
\hline $1100^{\circ} \mathrm{C}, t=45 \mathrm{~s}$ (2nd drop) & $8.3 \times 10^{-7}$ & $8.3 \times 10^{-7}$ & $5.24 \times 10^{-8}$ & $2.9 \times 10^{-7}$ & $8.3 \times 10^{-7}$ & $2.18 \times 10^{-5}$ \\
\hline $1100{ }^{\circ} \mathrm{C}, t=30 \mathrm{~min}$ & $8.3 \times 10^{-7}$ & $6.54 \times 10^{-7}$ & $7.08 \times 10^{-8}$ & $4.51 \times 10^{-7}$ & $8.3 \times 10^{-7}$ & $2.53 \times 10^{-5}$ \\
\hline
\end{tabular}

with liquid $\mathrm{Cu}$ on graphite-coated $\mathrm{SiC}$ substrate (graphite layer of about 1 micron thickness) using the same testing procedure (non-contact heating) and under the same testing conditions, evidenced only slightly lower contact angle of $\sim 142^{\circ}$ (Table 1, data " $\mathrm{C}_{\mathrm{dSiC}}$ ") (see SUPLEMENT \#3), compared to that on bulk graphite.

The comparison of the results of this study with those given in the literature for the $\mathrm{Cu} / \mathrm{SiC}$ system is much more complicated because literature data are quite scattered and contradict (Table 1). Even for the same testing procedure of contact heating, both wetting and non-wetting were reported, depending on testing conditions and production history of $\mathrm{SiC}$ substrates. The highest contact angles of $150^{\circ}$ and $130^{\circ}$ were observed on polycrystalline $\mathrm{B}-\mathrm{SiC}$ substrates containing graphite and on pure $\mathrm{SiC}^{\mathrm{pc}}$, respectively (Ref 33), whereas on $\mathrm{SiC}$ single crystal in vacuum of $p=1.0 \times 10^{-4}$ mbar contact angle was $112^{\circ}$ (Ref 29). The smallest contact angles were observed on polycrystalline reaction-bonded $\mathrm{SiC}$ substrates $\left[83^{\circ}\right.$ in vacuum of $p=1.0 \times 10^{-4} \mathrm{mbar}(\operatorname{Ref} 32)$ and $\sim 60^{\circ}$ in a vacuum of $\left.p=1.33 \times 10^{-6} \operatorname{mbar}(\operatorname{Ref} 30)\right]$. The highest values of contact angles given in the literature are believed to be related with the effect of $\mathrm{SiC}$ oxidation since liquid $\mathrm{Cu}$ forms a high contact angle on $\mathrm{SiO}_{2}\left(120-140^{\circ}\right.$ (Ref 39, 40) (Table 1, data " $\mathrm{SiO}_{2}$ ").

From the first look on the above comparisons, one may suggest that liquid $\mathrm{Cu}$ does not recognized the graphene layer because its contact angle on the $\mathrm{C}_{\mathrm{Gn}} / \mathrm{SiC}$ substrate is most closely comparable to that on $\mathrm{SiC}$ than on graphite, hence supporting the graphene wetting transparency effect reported for water (Ref 19). However, in reality the situation is much more complicated and many other phenomena are involved in high-temperature interaction between liquid $\mathrm{Cu}$ and graphenecoated SiC. We suggest that the most important one is the rolling of the 1st drop along the substrate surface because it causes: (1) wetting hysteresis and the formation of dissimilar left and right contact angles, (2) detachment of the fragments of graphene layer and their movement to the top of the drop.

Most probably, the observed drop rolling is related with gas release from the substrate as evidenced in real-time records of residual gas analyzer (Table 2, Fig. 16). As shown in Fig. 16(a), just before heating when corresponding vacuum of $p=1.20 \times 10^{-6}$ mbar was reached, the low amounts of $\mathrm{H}_{2} \mathrm{O}$ and $\mathrm{H}_{2}$ were recorded in the chamber. Heating to $200{ }^{\circ} \mathrm{C}$ caused only small increase in gasification from the $\mathrm{C}_{\mathrm{Gn}} / \mathrm{SiC}^{\mathrm{sc}}$ substrate (Fig. 16b). However, during further heating to the test temperature of $1100{ }^{\circ} \mathrm{C}$, high amounts of $\mathrm{CO}_{2}, \mathrm{CO}, \mathrm{C}, \mathrm{H}_{2} \mathrm{O}$ and
$\mathrm{H}_{2}$ are released and this effect is accompanied with increase in pressure inside vacuum chamber up to $p=2.18 \times 10^{-5} \mathrm{mbar}$, at the moment of squeezing of the 1 st drop from the capillary (Fig. 16c). Since dropping the 2nd drop does not change the degree of gasification, we suggest that gas release from the $\mathrm{C}_{\mathrm{Gn}}$ / $\mathrm{SiC}^{\text {sc }}$ contributed to rolling of the $\mathrm{Cu}$ drop and its apparently non-wetting behavior.

Comparison of the above results with those of our previous experience shows that the conditions used for substrate storage affect the volume of gases released during heating up to $200{ }^{\circ} \mathrm{C}$ (not shown in this study). Similar observations on the release of oxygen and another molecule from graphene-coated $\mathrm{SiC}$ during its heating was also reported by Kalbac et al. (Ref 41).

Another reason responsible for unusual behavior of the 1st $\mathrm{Cu}$ drop can be related with the changes in the structure and chemistry of the substrate surface during high-temperature heating under UHV. Among others, it can be caused from the difference in the coefficient of thermal expansions (CTE) of graphene $\left[-7.0 \times 10^{-6} \mathrm{~K}^{-1} \quad(\operatorname{Ref} 40)\right]$ and $\mathrm{SiC}$ $\left(4.0 \times 10^{-6} \mathrm{~K}^{-1}\right)$. Kalbac et al. (Ref 41) showed that upon heating to $800{ }^{\circ} \mathrm{C}$, bilayer graphene deposited on $\mathrm{SiO}_{2} / \mathrm{Si}$ by CVD process induces stress due to CTE mismatch of contacting materials and this stress strongly influences the bottom (substrate-side) layer of graphene, whereas its top layer remains almost unaffected. Weis et al. (Ref 42) suggested that it is related with weak bonding between graphene layers subsequently resulting in more pronounced wrinkling of the top layer.

Whatever is the mechanism responsible for the degradation of graphene (cracking due to CTE mismatch, chemical etching by liquid $\mathrm{Cu}$, mechanical detachment by rolling drop), it causes the formation of discontinuities in the layer that in turn accelerates the interaction between liquid $\mathrm{Cu}$ and graphene-free SiC. This process is accompanied with (Ref 35): (1) the dissolution of $\mathrm{SiC}$ in liquid copper, (2) the formation of interfacial reaction products, and (3) the formation of $\mathrm{SiC}$ on the top of the drop (Ref 35).

In this study, the presence of silicon on the surface of both the 1st and 2nd drop has been identified and it presents an experimental evidence of the dissolution of the $\mathrm{SiC}$ substrate in liquid $\mathrm{Cu}$. On the other hand, it was observed that the growth of intermediate layer was much slower in the 1st drop than in the 2nd one thus suggesting dissimilar substrate surface conditions for two droplets. Taking into account that the 2 nd drop was deposited on postponed area of drop rolling, characterized by weaker signal from graphene, compared to as-received state, we 
suggest that the contact of graphene layer with the 1st drop and its subsequent rolling resulted not only in reconstruction of graphene layer but even its partial removal from SiC substrate thus making easy further direct interaction between Liquid $\mathrm{Cu}$ and graphene-free substrate surface.

Copper does not form any compounds with carbon and it dissolves very little carbon both in solid and liquid states. Therefore, high-temperature interaction in the $\mathrm{Cu}-\mathrm{C}$ system is widely accepted as non-reactive showing non-wetting behavior and weak $\mathrm{Cu}-\mathrm{C}$ bonding, independently on the allotropic form of carbon, such as graphite (Ref 10), glassy-like carbon (Ref 11 ), diamond (Ref 12), carbon fibers (Ref 13).

The acceleration of reactivity in the $\mathrm{Cu} / \mathrm{SiC}$ system is affected by the presence of pristine $\mathrm{SiC}$ surface (after removing graphene layer). Absence of $\mathrm{SiO}_{2}$ normally present on the surface of $\mathrm{SiC}$ monocrystals was due to the sublimation method by which graphene was produced. The said method consists in a sublimation of $\mathrm{Si}$ from the surface under the conditions of UHV and high temperature (Ref 43). Carbon undergoes rearrangement to form a layer of graphene, which acts as a barrier to the $\mathrm{SiC}$ substrate oxidation. That indicates that the layer of graphene under the 2 nd $\mathrm{Cu}$ drop was totally degraded and was not a barrier to mass transport as for $1 \mathrm{st} \mathrm{Cu}$ drop whose intermediate layer was much thinner.

Another experimental evidence of absence of graphene layer in the place where the second drop was deposited is the hexagonal shape of a solid-like interface formed under second droplet. The appearance of the solid-like interface as a pyramid with hexagonal base shape has revealed that the reaction of $\mathrm{Cu}$ with substrate is controlled solely by the crystallographic nature of $\alpha$-SiC (Ref 31).

Therefore, it cannot be excluded that under the conditions of our experiment, a similar phenomenon might have happened between graphene with liquid $\mathrm{Cu}$ : (1) destruction of graphene layer by $\mathrm{C}$ dissolution in $\mathrm{Cu}$; (2) growth of graphene on molten $\mathrm{Cu}$ drop surface.

Although the dissolution of $\mathrm{C}$ in molten $\mathrm{Cu}$ is extremely low (0.02 at.\%) (Ref 41, 44) and molten $\mathrm{Cu}$ was saturated in graphite capillary, the partial or complete dissolution of graphene cannot be entirely excluded. Fuks et al. showed that after heat treatment even at $1000{ }^{\circ} \mathrm{C}$ by $1 \mathrm{~h}, \mathrm{Cu}$ reacted with $\mathrm{C}$ and the $\mathrm{Cu}-\mathrm{C}$ solid solution of $50 \mathrm{~nm}$ thickness was formed (Ref 44).

The partial or complete dissolution of graphene promotes dissolution of $\mathrm{SiC}$ in $\mathrm{Cu}$ in discontinuities. The dissolved $\mathrm{SiC}$ becomes additional $\mathrm{C}$ source for the formation of a new layer of graphene on $\mathrm{Cu}$ surface.

The presence of uniform double-layered graphene (Ref 45) on the 2 nd $\mathrm{Cu}$ drop surface revealed in Raman spectra suggests that it could be obtained by means of growth of graphene sheets on liquid $\mathrm{Cu}$.

A uniform hexagonal graphene flakes growth on liquid $\mathrm{Cu}$ drop at $1080{ }^{\circ} \mathrm{C}$ under $\mathrm{CH}_{4}$ flow was reported by Geng et al. (Ref 46). They demonstrated that the use of molten $\mathrm{Cu}$ is particularly effective means for controlling the nucleation process in graphene CVD synthesis and results in the production of uniform, single-layered, self-aligned, large-sized, single-domain graphene sheets and continuous monolayer film. Therefore, it cannot be excluded that during graphene formation, an additional process could occur, mainly re-knitting of sheets.

The pieces of the graphene layer detached from $\mathrm{SiC}$ surface layer (mechanical detaching by the 1st drop) can flow on the top surface of $\mathrm{Cu}$ drop where it can react with single carbon atoms (from dissolved $\mathrm{SiC}$, graphene or graphite capillary) forming new graphene sheets. During this process, the selfhealing of graphene sheets can occurs.

Similar self-healing process was described by Zan et al. (Ref 47) who observed that in the presence of metal, graphene can be etched on the nanoscale under. This phenomenon is accompanied by either knocking of carbon atoms out from neighboring edges or supplying by nearby hydrocarbon contamination patches.

A number of various phenomena can occur at the same time, wherefrom it follows that clarification of the wetting behavior of graphene in contact with molten $\mathrm{Cu}$ requires additional research.

\section{Conclusions}

Studies of the interaction between liquid metal and graphene-coated monocrystalline $\mathrm{SiC}$ substrate are characterized by high degree of intricacy and require special methods and procedures developed in order to test the specific nature of interactions between $2 \mathrm{D}$ materials at high temperature. The tests made with liquid $\mathrm{Cu}$ at $1100{ }^{\circ} \mathrm{C}$ confirm the complexity of interactions, evidenced also during tests with liquid $\mathrm{Sn}$ carried out at $350{ }^{\circ} \mathrm{C}(\operatorname{Ref} 20)$.

The behavior of the $\mathrm{Cu}$ drop in few attempts to detach it from the graphene-coated $\mathrm{SiC}$ substrate by rising up a graphite capillary showed a strong adhesion of the liquid $\mathrm{Cu}$ to the $\mathrm{SiC}$. Similar behavior of the $\mathrm{Cu}$ drop took place with graphene-free $\mathrm{SiC}$ substrate, while with graphite substrate, the $\mathrm{Cu}$ drop was easily detached without raising the substrate. These observations can be considered as indirect experimental evidence of the wetting transparency of graphene layer for liquid $\mathrm{Cu}$.

The results of SEM investigations and Raman spectroscopy studies suggest that the presence of graphene layer on the $\mathrm{SiC}$ substrate suppresses but does not completely prevent chemical interaction between liquid $\mathrm{Cu}$ drop and $\mathrm{SiC}$. Both chemical degradation (etching) and mechanical degradation of the graphene layer are responsible for the formation of discontinuities in the graphene layer. This in turn resulted in mass transfer through the interface and in changes of structure and chemistry of the drops and the interfaces formed. This effect is more pronounced for the second drop deposited on the path made by the first drop after its rolling.

\section{Acknowledgment}

The authors are grateful to the National Centre for Research and Development for financial support (Project No. GRAF-TECH/ NCBR/10/29/2013 "Novel graphene reinforced metal matrix composites for power and electronic industry").

\section{Open Access}

This article is distributed under the terms of the Creative Commons Attribution 4.0 International License (http://creativecommons.org/ licenses/by/4.0/), which permits unrestricted use, distribution, and reproduction in any medium, provided you give appropriate credit to the original author(s) and the source, provide a link to the Creative Commons license, and indicate if changes were made. 


\section{References}

1. S.R. Bakshi, D. Lahiri, and A. Agarwal, Carbon Nanotube Reinforced Metal Matrix Composites-A Review, Int. Mater. Rev., 2008, 55(1), p 41-64

2. P.H.G. Kumar and M.A. Xavior, Graphene Reinforced Metal Matrix Composite (GRMMC) a Review, Procedia Eng., 2014, 97, p 1033-1040

3. A.D. Moghadam, E. Omrani, P.L. Menezes, and P.K. Rohatgi, Mechanical and Tribological of Self Lubricating Metal-Matrix Nanocomposites Reinforced by Carbon Nanotubes (CNTs) and Graphene (Review), Compos. B, 2015, 77, p 402-420

4. K. Zhang, Fabrication of Copper Nanoparticles/Graphene Oxide Composite for Surface-Enhanced Raman Scattering, Appl. Surf. Sci., 2012, 258, p 7327-7329

5. J. Wang, Z. Li, G. Fan, Z. Chen, and D. Zhang, Reinforcement with Graphene Nanosheets in Aluminium Matrix Composites, Scripta Mater, 2012, 66, p 594-597

6. K. Jagaannadham, Thermal Conductivity of Copper-Graphene Composite Films Synthesized by Electrochemical Deposition with Exfoliated Graphene Platelets, Metall. Mater. Trans., 2012, 43B, p 316-324

7. E.Y. Nzoma, A. Gulliet, and P. Pareige, Nanostructired Multifilamentary Carbon-Copper Composites: Fabrication, Microstructural Characterization, and Properties, J. Nanomater, 2012, https://doi.org/10.1155/ 2012/360818

8. M. Homa, N. Sobczak, A. Gazda, A. Siewiorek, A. Kudyba, K. Pietrzak, K. Frydman, D. Wójcik-Grzybek, and A. Strojny-Nędza, Thermophysical Properties of Ag-C Composites, Ceram. Mater., 2015, 67(3), p 13-24 ((in Polish))

9. Z. Xu and M.J. Buehler, Interface Structure and Mechanics Between Graphene and Metal Substrates: A First-Principles Study, J. Phys. Condens. Matter, 2012, 22, p 485301. https://doi.org/10.1088/09538984/22/48/485301

10. G. Chen, F. Wu, C. Liu, V.V. Silberschmidt, and Y.C. Chan, Microstructures and Properties of New Sn-Ag-Cu Lead-Free Solder Reinforced with Ni-Coated Graphene Nanosheets, J. Alloy. Compd., 2016, 656, p 500-590

11. A. Sharma, D.E. Xu, J. Chow, M. Mayer, H.-R. Sohn, and J. Pil Jung, Electromigration of Composite $\mathrm{Sn}-\mathrm{Ag}-\mathrm{Cu}$ Solder Bumps, Electron. Mater. Lett., 2015, 11(6), p 1072-1077

12. X.D. Liu, Y.D. Han, H.Y. Jing, J. Wei, and L.Y. Xu, Effect of Graphene Nanosheets Reinforcement on the Performance of Sn-Ag-Cu Lead-Free Solder, Mater. Sci. Eng. A, 2013, 562, p 25-32

13. K. Nagarkar, S. Chauhan, F. Ahmad, and A. Gowda, Graphene for Next-Generation Electronics Packaging, Chip Scale Rev., 2013, 17(5), p 20-25

14. J. Rafiee, M.A. Rafiee, Z.Z. Yu, and N. Koratkar, Superhydrophobic to Superhydrophylic Wetting Control in Graphene Films, Adv. Mater, 2010, 22, p 2151-2154

15. K. Xu and J.R. Heath, Contact with What, Nat. Mater, 2013, 12, p $872-873$

16. G.T. Kim, S.J. Gim, S.M. Cho, N. Koratkar, and I.K. Oh, WettingTransparent Graphene Films for Hydrophobic Water-Harvesting Surfaces, Adv. Mater., 2014, 26, p 5166-5172

17. A. Kozbial, Z. Li, J. Sun, X. Gong, F. Zhou, Y. Wang, H. Xu, H. Liu, and L. Li, Understanding the Intrinsic Water Wettability of Graphite, Carbon, 2014, 74, p 218-225

18. C. Shih, Q.H. Wang, S. Lin, K.-C. Park, Z. Jin, M.S. Strano, and D. Blankschtein, Breakdown in the Wetting Transparency of Graphene, Phys. Rev. Lett., 2012, 109(17), p 1-5

19. J. Rafiee, X. Mi, H. Gullapalli, A. Thomas, F. Yavari, Y. Shi, P. Ajayan, and N. Koratkar, Wetting Transparency of Graphene, Nat. Mater, 2012, 11, p 217-222

20. N. Sobczak, J.J. Sobczak, A. Kudyba, M. Homa, G. Bruzda, M. Grobelny, M. Kalisz, K. Strobl, R. Singhal, and M. Monville, Wetting Transparency of Graphene Deposited on Copper in Contact with Liquid Tin, Trans. Foundry Res. Inst., 2014, LIV(3), p 3-11

21. W. Strupinski, K. Grodecki, A. Wysmolek, R. Stepniewski, T. Szkopek, P.E. Gaskell, A. Grüneis, D. Haberer, R. Bozek, J. Krupka, and J.M. Baranowski, Graphene Epitaxy by Chemical Vapor Deposition on SiC, Nano Lett., 2011, 11(4), p 1786-1791

22. R. Asthana, N. Sobczak, Wettability, Spreading, and Interfacial Phenomena in High-Temperature Coatings, 2000, JOM-e 52(1).
http://www.tms.org/pubs/journals/JOM/0001/Asthana/Asthana-0001-text. html. Accessed Jan 2000

23. N. Sobczak, R. Nowak, W. Radziwill, J. Budzioch, and A. Glenz, Experimental Complex for Investigations of High-Temperature Behaviour of Molten Metals in Contact with Refractory Materials, Mat. Sci Eng., 2008, A495, p 43-49

24. L. Liggieri and A. Passerone, An Automatic Technique for Measuring the Surface Tension of Liquid Metals, High Temp. Technol., 1989, 7, p 80-86

25. ASTRA Reference Book, IENI, Report, Oct. 2007

26. Z. Lin, X. Ye, J. Han, Q. Chen, P. Fan, H. Zhang, D. Xie, H. Zhu, and M. Zhong, Precise Control of the Number of Layers of Graphene by Picosecond Laser Thinning, Sci. Rep., 2015, 5, p 11662

27. N. Sobczak, J. Sobczak, P. Rohatgi, M. Książek, W. Radziwiłł, J. Morgierl, Interaction Between Ti or Cr Containing Copper Alloys and Porous Graphite Substrate, in Proc. 2nd Int Conf. High Temperature Capillarity, ed. by N. Eustathopoulos, N. Sobczak (eds), 1997, p 145-151

28. G.G. Gnesin and YuV Naidich, Contact Reaction of Silicon Carbide with Fused Copper, Poroshkovaya Metallurgiya, 1969, 2(74), p 57-63

29. B.K. Nogi and K. Ogino, Characteristic Wettability of SiC by Liquid Pure Cu, Trans. Jpn Inst. Metals, 1998, 29(10), p 805-811

30. M. Shimbo, M. Naka, and I. Okamoto, Wettability of Silicon Carbide by Aluminium, Copper and Silver, J. Mater. Sci. Lett., 1989, 8, p 663-666

31. C. Rado, B. Drevet, and N. Eustathopoulos, The Role of Compound Formation in Reactive Wetting: The $\mathrm{Cu} / \mathrm{SiC}$ System, Acta Mater, 2000, 48, p 4483-4491

32. P. Nikolopoulos, S. Agathopoulos, G.N. Angelopoulos, A. Naoumidis, and H. Grübmeier, Wettability and Interfacial Energies in SiC-Liquid Metal Systems, J. Mater. Sci., 1992, 27, p 139-145

33. J. Guo Li, Wettability of Silicon Carbide by Liquid Silver and Binary Silver-Silicon Alloy, Mater. Lett., 1994, 18, p 291-298

34. ChP Deck and K. Vecchio, Prediction of Carbon Nanotubes Growth Success by the Analysis of Carbon-Catalyst Binary Phase Diagrams, Carbon, 2006, 44, p 267-275

35. G.A. Lopez and E.J. Mittemeijer, The Solubility of $\mathrm{C}$ in Solid $\mathrm{Cu}$, Scripta Mater, 2004, 51, p 1-5

36. D. Fuks, K.C. Mudim, L.A.C. Malbouisson, A. Berner, S. Dorfman, and D.E. Ellis, Carbon in Copper and Silver: Diffusion and Mechanical Properties, J. Mol. Struct., 2001, 539, p 199-214

37. C. Mattevi, H. Kim, and M. Chhowalla, A Review of Chemical Vapor Deposition of Graphene on Copper, J. Mater. Chem., 2011, 21, p 3324 3334

38. S.M. DeVincent, D.L. Ellis, G.M. Michal, Graphite/copper alloy interfacial energies determined using the sessile drop method, NASA Contractor Report 187087

39. O. Dezellus and N. Eustathopoulos, The Role of Van Der Waals Interactions on Wetting and Adhesion in Metallic/Carbon Systems, Scr. Mat., 1999, 40(11), p 1283-1288

40. M. Barlak, J. Piekoszewski, Z. Werner, B. Sartowska, L. Waliś, W. Starosta, J. Keirzek, C. Pochrybniak, and E. Kowalska, Wettability of Carbon and Silicon Carbide Ceramics Induced by Their Surface Alloying with $\mathrm{Zr}$ and $\mathrm{Cu}$ Elements Using High Intensity Pulsed Plasma Beams, Nukleonika, 2012, 57(4), p 477-483

41. M. Kalbac, O. Frank, and L. Kavan, Effects of Heat Treatment on Raman Spectra of Two-Layer ${ }^{12} \mathrm{C} /{ }^{13} \mathrm{C}$ Graphene, Chem. Eur. J., 2012, 8, p 11377-13884

42. J.E. Weis, S. Costa, O. Frank, and M. Kalbac, Heating Isotopically Labelled Bernal Stacked Graphene: A Raman Spectroscopy Study, J. Phys. Chem. Lett., 2014, 5, p 549-554

43. P. Shen, H. Fujii, and K. Nogi, Wetting Adhesion and Diffusion in $\mathrm{Cu}-$ $\mathrm{Al} / \mathrm{SiO}_{2}$ System at $1473 \mathrm{~K}$, Scr. Mat., 2005, 52, p 1259-1263

44. W. Gao and R. Huang, Thermomechanics of Monolayer Graphene: Rippling, Thermal Expansion Coefficient and Elasticity, J. Mech. Phys. Solids, 2014, 66, p 42-58

45. H. Abderrazak, E.S.B.H. Hmida, Silicon Carbide: Synthesis and Properties. www.intechopen. Accessed Jan 2000

46. D. Geng, B. Wu, Y. Guo, L. Huang, Y. Xue, J. Chen, G. Yu, L. Jiang, W. Hu, and Y. Liu, Uniform Hexagonal Graphene Flakes and Films Grown on Liquid Copper Surface, PNAS, 2012, 109, p 7993-7996

47. R. Zan, Q.M. Ramasse, U. Bangert, and K.S. Novoselov, Graphene Reknits Its Holes, Nano Lett., 2012, 12(8), p 3936-3940 